\title{
Aspectos Produtivos do Capim-Elefante (Pennisetum purpureum, Schum.) cv. Roxo no Brejo Paraibano ${ }^{1}$
}

\author{
Estácio Alves dos Santos ${ }^{2}$, Divan Soares da Silva ${ }^{3}$, José Leite de Queiroz Filho ${ }^{3}$
}

\begin{abstract}
RESUMO - O trabalho foi realizado com o objetivo de verificar o efeito de diferentes alturas de corte sobre a produtividade do capimelefante cv. Roxo em épocas de seca e chuva no Brejo paraibano. O esquema experimental foi um fatorial 4 x 2 , sendo quatro alturas de corte $(0,15,30$ e $45 \mathrm{~cm})$, duas épocas (períodos seco e chuvoso) e quatro blocos. Foram avaliadas as produções por hectare de massa verde (MV), matéria seca total (MS), de folhas (MSF) e colmos (MSC) e proteína bruta (PB). Após o corte de uniformização, efetuaram-se dois cortes no período seco em intervalos de 90 dias e três no período chuvoso em intervalos de 60 dias. Não houve interação entre altura de corte e a época. Entretanto, à medida que se elevou a altura do corte, reduziram-se as produções de MV, MS e MSC. As produções de PB e MSF não diferiram. Quando elevadas as alturas dos cortes de 0 para $45 \mathrm{~cm}$, houve redução de aproximadamente $33 \%$ na produção para MV, 24,83\% para MSF e 60\% para MSC. Os cortes no período seco foram mais produtivos em relação aos da época chuvosa. As médias das produções de MS, MV, MSF, MSC e PB foram, respectivamente, 4,12; 21,19; 2,65; 1,47 e 0,32 t/ha no período seco e 12,44; 2,$45 ; 1,81 ; 0,54$ e 0,17 t/ha no período chuvoso.
\end{abstract}

Palavras-chave: alturas de corte, intervalos de corte, produção de forragem

\section{Productive Aspects of Elephant Grass (Pennisetum purpureum, Schum.) var. Roxo in Paraíba Swamp Region}

\begin{abstract}
This work was carried to evaluate the effect of different cutting heights on the productivity of elephant grass var. Roxo in dry and rainy season in the Paraíba swamp region. A randomized complete block design in a 4 X 2 factorial, arrangement, with four cutting heights $(0,15,30$ and $45 \mathrm{~cm})$, two periods (dry and rainy seasons) and 4 blocks were used. It was evaluated the production/ ha of fresh matter (FM), dry matter (DM), leaves (DML), stems (DMS) and crude protein (CP). After the uniformity cut, two cuts in dry season with 90 days interval and three cuts in the rainy season with 60 days interval were made. There was no interaction between seasons and cutting heights. However, as cutting height increased, the values of FM, DM and DMS productions decreased. The production of PB and MSF did not differ. When the cutting heights was evaluated from 0 to $45 \mathrm{~cm}$, there was a reduction of the productions of approximately $33 \%$ for FM, $24.83 \%$ for DML and $60 \%$ for DMS. The cuts in the dry season were more productive than in the rainy season. The production averages of DM, FM, LDM, SDM and CP were: $4.12,21.19,2.65,1.47$ and 0.32 t/ha in the dry season, and $12.44,2.45,1.81,0.54$ and 0.17 ton/ha in the rainy season, respectively.
\end{abstract}

Key Words: cutting heights, cutting intervals, forage production

\section{Introdução}

A produção de forragem na maior parte das áreas agrícolas do Nordeste constitui-se limite para a exploração pecuária, decorrente principalmente da grande escassez de áreas agricultáveis e dos baixos índices pluviométricos. As forrageiras nativas, embora de boa qualidade, são desfavorecidas pela periodicidade das chuvas, encurtando o seu ciclo produtivo como mecanismo de resistência à aridez da região, não podendo, assim, se constituir em um suporte forrageiro disponível por longo período. Por outro lado, as espécies forrageiras exóticas introduzidas na região são de difícil adaptação; chegam a dar bons rendimentos no período das águas, mas não suportam estresses climáticos.

O capim-elefante é uma forrageira perene, com alta taxa de crescimento, alta produtividade, bom valor nutritivo e de grande aceitação pelos animais, tanto picada no cocho como em pastejo direto. Os vários estudos com capim-elefante revelaram que tanto a escolha da cultivar a ser utilizada como a adaptação desta às condições edafo-climáticas e ao manejo empregado são indispensáveis ao seu desempenho produtivo.

Avaliando a produtividade do capim-elefante, QUEIROZ FILHO et al. (1996) obtiveram, com cortes em intervalos de 60 dias, produções de matéria seca

\footnotetext{
1 Parte da Dissertação de Mestrado do primeiro autor. Trabalho financiado pela CAPES.

2 Pós-Graduando em Produção Animal, UNESP - Jaboticabal, SP -Rod. Paulo D. Castellane, Km 5, CEP 14870-000.E.mail:estacio@fcav.unesp.br

3 Professor do DZ/CCA/UFPB, Campus III, Areia-PB. CEP 58.397-000.
} 
de 3,2; 2,6; 3,0; e 3,1 t/ha com as cultivares Roxo, Cameroon, Gramafante e Mineirão, realizando cortes rentes ao solo durante três anos de experimento na região do Brejo Paraibano. NASCIMENTO et al. (1995), comparando as mesmas cultivares naquela região, constataram que em dois anos de cultivo a cultivar Roxo apresentou a maior produção de proteína bruta por área, também realizando cortes rentes ao solo na frequência de 60 dias. COSTA e OLIVEIRA (1993), submetendo a cultivar Roxo a três idades de corte, verificaram aos 76 dias maior produção de matéria seca e aos 45 dias, maior produção de proteína bruta por área.

ALCÂNTARA et al. (1980), no Estado de São Paulo, observaram produções de 51,9 $\mathrm{t}$ de MS/ha por ano com a cultivar Taiwan A-144. GONÇALVES e COSTA (1991) obtiveram variação na produção anual de matéria seca da parte aérea da ordem de 19,69 para 25,29 t/ha, em média, quando da variação da altura de corte de 5 para $30 \mathrm{~cm}$ do solo. Para os intervalos de 42 e 84 dias, a produção de MS foi de 22,79 e 30,73t/ha, respectivamente.

GONÇALEZetal. (1981), avaliando quatro cultivares de capim-elefante cortadas com 20 e $40 \mathrm{~cm}$ de altura, em intervalos de cortes de 45, 90, 135 e 180 dias, verificaram, com o aumento do intervalo, variação linear crescente na produção de matéria seca por hectare, bem como aumentos proporcionais em proteína bruta. A altura do corte de $20 \mathrm{~cm}$ resultou em maior produção de forragem em relação a $40 \mathrm{~cm}$.

CANTO et al. (1974) não encontraram diferença na produção de forragem para plantas de capimelefante cortadas com 5, 10, 15, 20 e $25 \mathrm{~cm}$. Já SANTANA et al. (1989), estudando a interação entre frequência e altura de corte nas cultivares Cameroon, Mineiro e Napier de Goiás, concluíram que a maior produtividade ocorre combinando cortes rentes ao solo com intervalos de oito semanas.

ACUNHA e COELHO (1997), trabalhando com o capim-elefante Anão (cv Mott), obtiveram produções de 2,74; 4,16 e 6,26 t de MS/ha para cortes efetuados aos 56, 84 e 112 dias, respectivamente. Para a mesma cultivar, COSTA et al. (1995) recomendaram cortes na altura de $15 \mathrm{~cm}$ do solo em intervalos de 70 dias, com os quais obtiveram 23,09 t de matéria seca por hectare/ano.

O objetivo deste trabalho foi estudar o efeito de alturas de corte sobre a produtividade do capimelefante (Pennisetum purpureum, Schum) cv. Roxo, e sua distribuição nos períodos seco e chuvoso no Brejo Paraibano.

\section{Material e Métodos}

O experimento foi desenvolvido na área de forragicultura do Departamento de Zootecnia do CCA-UFPB, Campus III, Areia-PB, situada a 574,02 m de altitude, $6^{\circ} 50^{\prime} \mathrm{S}$ de latitude e $35^{\circ} 42^{\prime} \mathrm{W}$ de longitude. O clima é classificado como do tipo As quente e úmido, com chuvas de outono-inverno, pluviosidade média em torno de $1400 \mathrm{~mm}$ anuais. A temperatura média anual oscila entre 23 e $24^{\circ} \mathrm{C}$. O solo é do tipo Podzólico Vermelho-Amarelo (BRASIL, 1973), com textura arenosa (SANTOS, 2001a).

O plantio foi feito em 28/07/94 em parcelas de $15 \mathrm{~m}^{2}$, em covas com espaçamento de $70 \times 80 \mathrm{~cm}$, utilizando segmentos de colmo medindo cerca de $30 \mathrm{~cm}$ e contendo três gemas. Por ocasião do plantio, foram aplicados em cobertura $30 \mathrm{~kg} / \mathrm{ha}$ de $\mathrm{P}_{2} \mathrm{O}_{5}, 20 \mathrm{~kg} / \mathrm{ha}$ de $\mathrm{K}_{2} \mathrm{O}$. Dois anos após o plantio da forrageira foi procedida análise do solo; três meses antes do início do experimento foi dado um corte rente ao solo em toda a capineira e feita a correção do pH do solo com aplicação de 2,8 t/ha de calcário e adubação em cobertura aplicando $30 \mathrm{~kg}$ de $\mathrm{P}_{2} \mathrm{O}_{5}, 20 \mathrm{~kg}$ de $\mathrm{K}_{2} \mathrm{O}$ e $50 \mathrm{~kg}$ de $\mathrm{N}$ por hectare na forma de superfosfato triplo, cloreto de potássio e sulfato de amônia, respectivamente. Em 09/96 fez-se um corte de uniformização das parcelas nas alturas de $0,15,30$ e $45 \mathrm{~cm}$ e aplicação de $50 \mathrm{~kg} / \mathrm{ha}$ de $\mathrm{N}$ pelo mesmo sistema, iniciando-se então o período experimental. As aplicações de adubos seguiram recomendações feitas com base em análise do solo (SANTOS, 2001a).

Foram avaliados os efeitos de quatro alturas de corte $(0,15,30$ e $45 \mathrm{~cm})$ sobre a produção do capimelefante cv. Roxo em diferentes épocas do ano; para tanto, após o corte de uniformização, efetuaram-se três cortes em intervalos de 60 dias, durante o período chuvoso (janeiro a junho), e dois cortes em intervalos de 90 dias, no período de menor precipitação (julho a dezembro). Os cortes do capim foram efetuados manualmente e, para efeito de amostragem, considerou-se área útil de $8,4 \mathrm{~m}^{2}$ por parcela. A partir dos resultados, estimaram-se as produções de massa verde, matéria seca da parte aérea e produção de matéria seca de folhas, colmos e proteína bruta.

O material coletado foi pesado em balança com capacidade para $20 \mathrm{~kg}$. De cada parcela foi retirada uma amostra de 3 a 5 perfilhos inteiros, cortados em pedaços de 3 a $4 \mathrm{~cm}$, pesados e colocados em estufa com ventilação forçada a $60^{\circ} \mathrm{C}$ durante 72 horas; 
após este tempo estas amostras foram pesadas, para se calcular a produção de matéria pré-seca; em seguida fez-se a separação das frações de colmos e folhas, pesando-as separadamente em balança eletrônica com duas casas decimais para se estimar a produção de folhas e colmos por tratamento. As frações foram novamente misturadas e as amostras, moídas em moinho com peneira de 40 mesh, acondicionado-as em frascos de vidros, para posterior análise.

A produtividade de proteína bruta foi calculada a partir do teor de $\mathrm{N}$ na forragem, obtido pelo método Semimicro de Kjeldahl (SILVA, 1991), com base na produção total de matéria pré-seca.

O delineamento experimental foi o de blocos casualizados em esquema fatorial $4 \times 2$, sendo quatro alturas de corte $(0,15,30$ e $45 \mathrm{~cm})$, duas épocas, (seca e chuvas) e quatro repetições, conforme modelo matemático a seguir:

$$
Y_{i j k}=\mu+\alpha_{i}+E_{j}+\beta_{k}+(\alpha E) i_{j}+e_{i j k},
$$

em que $Y_{i j k}$ é o valor observado relativo à parcela que recebeu o corte na altura i na época j e no bloco k; $\mu$, a média geral; $\alpha_{i}$, o efeito da i-ésima altura de corte; $E_{j}$, o efeito da j-ésima época; $\beta_{k}$, o efeito do k-ésimo bloco; $\alpha E$, efeito da interação altura x época de corte; e $\mathrm{e}_{\mathrm{ijk}}$, o erro aleatório associado à observação.

A análise de variância foi realizada pelo GLM Procedures (SAS, 1993) e as médias obtidas foram comparadas pelo teste Tukey a 5\% de significância.

\section{Resultados e Discussão}

Constam da Tabela 1 os valores médios obtidos neste ensaio e as equações de regressão de cada variável estudada em função das alturas de corte. A análise de variância mostrou que não houve efeito da interação $(\mathrm{P}>0,05)$ entre altura e época dos cortes nos intervalos utilizados; no entanto houve efeito significativo $(\mathrm{P}<0,05)$ das alturas dos cortes sobre a produção de massa verde (MV), matéria seca (MS) e colmo (MSC). As produções de matéria seca de folhas (MSF) e proteína bruta por área (PB) não diferiram $(\mathrm{P}>0,05)$ com as alturas de corte.

A partir das equações de regressão (Tabela 1) obtidas, constatou-se que o manejo dos cortes teve influência sobre a produção da forrageira; observou-se que, para cada centímetro de elevação nas alturas dos cortes, houve redução média de $151,3 \mathrm{~kg} / \mathrm{ha}$ na produção de massa verde, $22,8 \mathrm{~kg} / \mathrm{ha}$ na produção de matéria seca, $7,3 \mathrm{~kg} / \mathrm{ha}$ na produção de folhas e $12,5 \mathrm{~kg} / \mathrm{ha}$ no peso seco de colmos por corte. As equações permitiram estimar perdas consideráveis de matéria seca de forragem, que se elevaram proporcionais com a elevação da altura do corte. A elevação de apenas um centímetro na altura do corte provocou desperdício de proteína bruta de aproximadamente $1,5 \mathrm{~kg} / \mathrm{hectare} /$ corte (médias de 5 cortes/ano), quantidade suficiente para atender a exigência diária de duas vacas em reprodução, com $400 \mathrm{~kg}$ de PV e ganho diário em torno de $700 \mathrm{~g}$ (BOIN, 1992).

Quando considerados isoladamente, estes valores mostram-se relativamente baixos; no entanto, se extrapolados a variações maiores nas alturas dos cortes, podem-se verificar baixas consideráveis na disponibilidade de nutrientes por área cultivada desta forrageira. Esse fato desperta a atenção para a importância que se deve dar ao adequado manejo da capineira para maior aproveitamento da forragem

Na Figura 1, as curvas obtidas pelas equações de regressão seguem a mesma tendência nas duas épocas: redução com a elevação das alturas de corte para todas as variáveis, sendo que os cortes realizados no período de estiagem mostraram valores superiores $(\mathrm{P}<0,05)$ aos da época chuvosa e suas médias diferiram estatisticamente (Tabela 2).

Os cortes realizados rentes ao solo apresentaram produções de massa verde e matéria seca de colmo superiores aos cortes realizados a 30 e $45 \mathrm{~cm}$. A elevação dos cortes de 0 para $45 \mathrm{~cm}$ resultou em diminuição de aproximadamente $33 \%$ na produção anual de massa verde pela forrageira e de $60 \%$ da produção de colmos.

Considerando-se que a fração de colmos dessa forrageira no período de estiagem ficou em torno de $28 \%$ da MS produzida (SANTOS et al, 2000b) e que a presença dos colmos não depreciou qualitativamente a composição química da forrageira (SANTOS et al, 2000c), o resíduo deixado no campo constitui desperdício de forragem, apesar de sua maior parte ser composta por colmos.

As produções de matéria seca de folhas e proteína bruta por hectare não diferiram $(\mathrm{P}>0,05)$ com as alturas dos cortes e apresentaram valores médios de $2,23 \mathrm{t} / \mathrm{ha}$ e $0,24 \mathrm{t} / \mathrm{ha} /$ corte, respectivamente. Estes resultados mostram-se contrários aos obtidos por WERNER et al. (1966), os quais, efetuando cortes baixos $(1-3 \mathrm{~cm})$, médios $(30-40 \mathrm{~cm})$ e altos $(70-80 \mathrm{~cm})$, em intervalos de quatro semanas com a cultivar Napier, obtiveram produções de matéria seca e proteína bruta por hectare mais elevadas, com aumento das alturas dos cortes. Segundo os autores, esta discrepância tem a ver com os intervalos com que se 
Tabela 1 - Valores médios das produções de massa verde (MV), matéria seca (MS) e proteína bruta (PB) da parte aérea, matéria seca de folhas (MSF) e matéria seca de colmos (MSC), em função da altura dos cortes e das equações de regressão obtidas para cada variável

Table 1 - Mean values of fresh matter (FM), dry matter (DM) of the aerial part, dry matter of leaves (DML), dry matter of stems (DMS) and crude protein $(C P)$ productions, in function of cutting heights and regression equations obtained for each variable

\begin{tabular}{|c|c|c|c|c|c|c|c|c|c|c|}
\hline \multirow[t]{2}{*}{$\begin{array}{l}\text { Variáveis } \\
\text { Variables }\end{array}$} & \multicolumn{4}{|c|}{$\begin{array}{c}\text { Alturas dos cortes, } \mathrm{cm} \\
\text { Cutting heights }\end{array}$} & \multirow[t]{2}{*}{$\begin{array}{l}\text { Médias } \\
\text { Means }\end{array}$} & \multirow[t]{2}{*}{$\begin{array}{l}\text { DMS } \\
M D S\end{array}$} & \multirow[t]{2}{*}{$\begin{array}{c}\text { Equações de regressão } \\
\text { Regression equations }\end{array}$} & \multirow[t]{2}{*}{$\mathrm{R}^{2}$} & \multirow[t]{2}{*}{ CV $(\%)$} & \multirow[t]{2}{*}{$\begin{array}{l}\text { Significância } \\
\text { Significance }\end{array}$} \\
\hline & 0 & 15 & 30 & 45 & & & & & & \\
\hline $\begin{array}{l}\mathrm{MV}(\mathrm{t} / \mathrm{ha}) \\
F M\end{array}$ & 20,94 & 17,82 & 15,88 & 14,02 & 17,17 & 3,37 & $\hat{Y}=20,571-0,1513 x$ & 0,92 & 14,07 & $* *$ \\
\hline $\begin{array}{l}\text { MS (t/ha) } \\
D M\end{array}$ & 3,75 & 3,65 & 3,01 & 2,82 & 3,31 & 0,92 & $\hat{Y}=3,8191-0,0228 x$ & 0,63 & 20,30 & $*$ \\
\hline $\begin{array}{l}\operatorname{MSF}(\mathrm{t} / \mathrm{ha}) \\
D M L\end{array}$ & 2,43 & 2,17 & 2,31 & 2,02 & 2,23 & 0,56 & $\hat{\mathrm{Y}}=2,3978-0,0073 \mathrm{x}$ & 0,83 & 17,89 & NS \\
\hline $\begin{array}{l}\operatorname{MSC}(\mathrm{t} / \mathrm{ha}) \\
D M S\end{array}$ & 1,33 & 1,11 & 0,76 & 0,82 & 1,00 & 0,5 & $\hat{Y}=1,2838-0,0125 x$ & 0,98 & 36,14 & $*$ \\
\hline $\begin{array}{l}\mathrm{PB}(\mathrm{t} / \mathrm{ha}) \\
C P\end{array}$ & 0,28 & 0,25 & 0,23 & 0,21 & 0,24 & 0,11 & $\hat{\mathrm{Y}}=0,2769-0,0015 \mathrm{x}$ & 0,99 & 15,00 & NS \\
\hline $\begin{array}{ll}\left({ }^{*}\right) & \text { Significat } \\
& \text { Significant } \\
\left({ }^{* *}\right) & \text { Significat } \\
& \text { Significant } \\
& \text { DMS }=\mathrm{D} \\
& M S D=\text { Mir } \\
& \mathrm{NS}=\mathrm{Nã} \\
& N S=\text { Non }\end{array}$ & $\begin{array}{l}\text { iva a } 5 \% \\
\text { at } 5 \% \text { by } \\
\text { iva a } 1 \% \\
\text { at } 1 \% \text { by } \\
\text { iferença } \\
\text { imum sigr } \\
\text { o-signific } \\
\text { significan }\end{array}$ & $\begin{array}{l}\text { pelo te } \\
\text { Tukey te } \\
\text { pelo te } \\
\text { Tukey te } \\
\text { nínima } \\
\text { ificant di } \\
\text { ante. }\end{array}$ & $\begin{array}{l}\text { te Tuke } \\
\text { st. } \\
\text { te Tuke } \\
\text { st. } \\
\text { ignificat } \\
\text { ference. }\end{array}$ & & & & & & & \\
\hline
\end{tabular}

Tabela 2 - Produção por corte do capim-elefante cv Roxo nos períodos seco e chuvoso (t,ha) Table 2 - Production per cut of elephant grass var. Roxo in the dry and rainy seasons (t/ha)

\begin{tabular}{|c|c|c|c|c|}
\hline $\begin{array}{l}\text { Variável } \\
\text { Variable }\end{array}$ & $\begin{array}{l}\text { Período seco } \\
\text { Dry season } \\
\end{array}$ & $\begin{array}{c}\text { Período chuvoso } \\
\text { Rainy season } \\
\end{array}$ & $\begin{array}{l}\text { DMS } \\
M S D\end{array}$ & $\mathrm{CV}(\%)$ \\
\hline Massa verde & $21,19^{\mathrm{A}}$ & $13,44^{\mathrm{B}}$ & 1,77 & 14,08 \\
\hline $\begin{array}{l}\text { Fresh mass } \\
\text { Matéria seca }\end{array}$ & $4,167^{\mathrm{A}}$ & $2,45^{\mathrm{B}}$ & 0,49 & 20,03 \\
\hline $\begin{array}{l}\text { Dry matter } \\
\text { Matéria seca de folhas } \\
\text { Dry matter of leaves }\end{array}$ & $2,65^{\mathrm{A}}$ & $1,81^{\mathrm{B}}$ & 0,29 & 17,89 \\
\hline $\begin{array}{l}\text { MS de colmos } \\
\text { Dry matter of stems }\end{array}$ & $1,47^{\mathrm{A}}$ & $0,54^{\mathrm{B}}$ & 0,27 & 36,14 \\
\hline $\begin{array}{l}\text { Proteína bruta } \\
\text { Crude protein }\end{array}$ & $0,32^{\mathrm{A}}$ & $0,17^{\mathrm{B}}$ & 0,11 & 15,00 \\
\hline
\end{tabular}

Médias, na linha, seguidas de mesma letra não diferem pelo teste de Tukey a 5\%.

Means, within a row, followed by same letter, did not differ by Tukey test at $5 \%$.

DMS = Diferença mínima significativa.

$M S D=$ Minimum significant difference.

${ }^{1}$ Médias de dois cortes (Mean of two harvests).

2 Médias de três cortes (Mean of three harvests).

realizam os cortes. Segundo esses autores, cortes muito baixos em intervalos reduzidos diminuem a produção.

As médias das produções por período encontram-se na Tabela 2. No período considerado seco, todas as variáveis em estudo foram superiores $(\mathrm{P}<0,05)$ em mais de $30 \%$ em relação aos valores observados no período chuvoso. Produções maiores foram obtidas por DAHER et al. (1997), que trabalhando com a mesma espécie obtiveram produções de matéria seca de $14.155 \mathrm{~kg} / \mathrm{ha}$ no período das águas e $5112 \mathrm{~kg} / \mathrm{ha}$ no período seco. Já CARVALHO et al. (1996) obtiveram produções 
$M V(V M)$

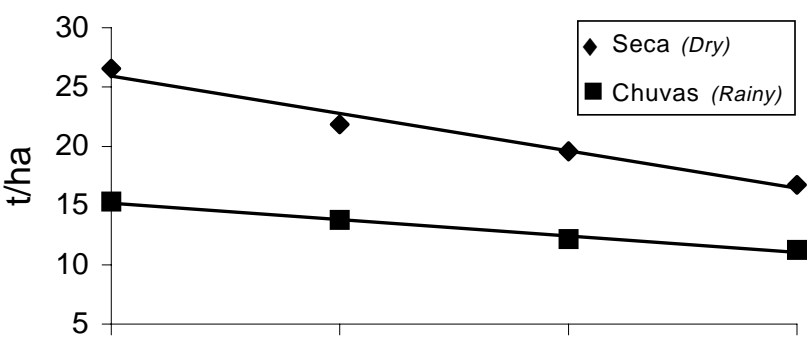

MS (DM)

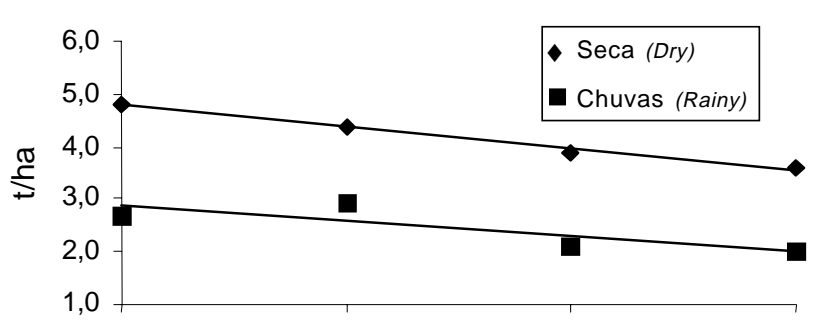

MSF (LDM)

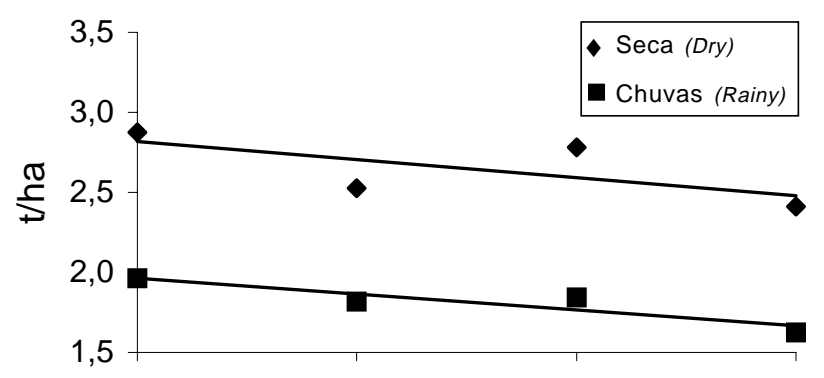

MSC (SDM)

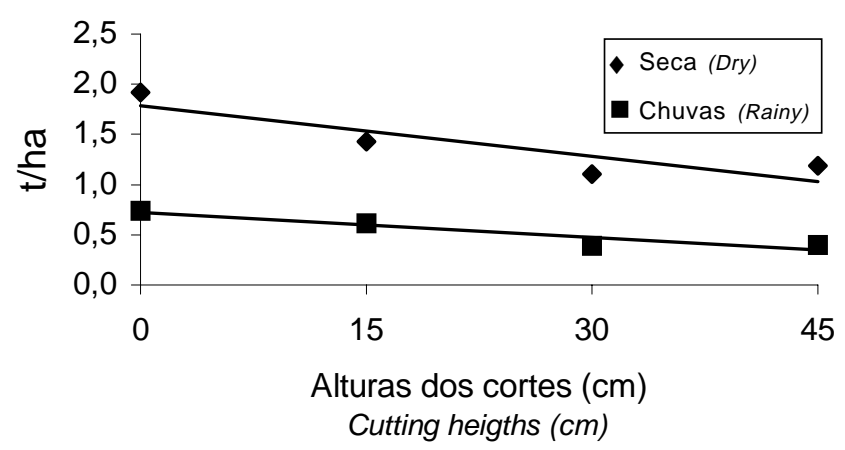

Figura 1 - Variação das produções de massa verde (MV), matéria seca (MS), matéria seca de folhas (MSF) e matéria seca de colmos (PMSC) do capimelefante cv. Roxo, cortado em diferentes alturas. Média de dois cortes no período seco e três cortes no período chuvoso.

Figure 1 - Variation of the fresh matter (VM), dry matter (DM), dry matter leaf (LDM) and stem dry matter (SDM) productions of elephant grass var. Roxo cutting at different heights. Averages of two cuttings in the dry season and three cuttings in the rainy season. de $14.463 \mathrm{~kg} / \mathrm{ha}$, efetuando dois cortes no período seco, e $19.542 \mathrm{~kg} / \mathrm{ha}$ de matéria seca, efetuando três cortes no período chuvoso e realizando adubações mineral e orgânica.

A produção média de matéria seca por corte observada em um ano de experimento foi semelhante aos resultados obtidos por GUEDES (1992), realizando três cortes no capim-elefante cv. Roxo na época mais chuvosa, que chegou a obter produção total de $11.732 \mathrm{~kg} / \mathrm{ha}$, e àqueles obtidos por QUEIROZ FILHO et al. (1998), média de $3.200 \mathrm{~kg} / \mathrm{ha}$ por corte com a mesma cultivar, realizando cortes rentes ao solo aos 60 dias.

$\mathrm{O}$ fato de, na época de estiagem, o capim ter-se apresentado mais produtivo (Tabela 2 ), com valores médios superiores $(\mathrm{P}<0,05)$ aos da época chuvosa, provavelmente se deva ao maior intervalo entre os cortes, que favoreceu o crescimento das hastes e expansão foliar das plantas. $\mathrm{O}$ corte que permitiu maior produtividade da forrageira foi efetuado no período de menor precipitação, intervalo que compreende os meses de setembro a dezembro, o que também se deu imediatamente após a realização da adubação mineral; naquele período, as plantas dispunham de boa radiação solar e temperatura favorável. A produção de forragem na estiagem foi favorecida também por alta precipitação ocorrida naquela época (Tabela 1). Observa-se que, na época de estiagem (julho, agosto, setembro, outubro, novembro e dezembro), ocorreu acúmulo de 494,10 mm, o que representou $34,6 \%$ da precipitação pluviométrica ocorrida no período experimental.

No presente ensaio, a produção de proteína bruta foi relativamente menor na estação chuvosa (Tabela 2), notadamente em função da menor produção de matéria seca naquele período. A produção média por corte mostrou-se, por sinal, inferior à obtida por COSTA et al. (1995) com o capim-elefante anão $(323,42 \mathrm{~kg} / \mathrm{ha} /$ corte $)$, em Rondônia, realizando cortes com 5,10 e $15 \mathrm{~cm}$ de altura aos 56 e 84 dias e NASCIMENTO (1997) com a cultivar Roxo cortada rente ao solo aos 40, 60, 80 e 100 dias na região do Brejo Paraibano.

Levando-se em conta o potencial produtivo do capim-elefante e os resultados de outros trabalhos desenvolvidos com cultivares desta forrageira, podese considerar que a produtividade foi relativamente baixa, o que pode ter sido causado pela pouca aplicação de adubo no estabelecimento, tendo em vista a exigência do capim-elefante quanto à fertilidade do solo. 


\section{Conclusões}

A elevação das alturas dos cortes no capim-elefante roxo reduziu a produção de massa verde, matéria seca da parte aérea e matéria seca de colmos por área.

A produtividade de proteína bruta do capimelefante Roxo não foi influenciada pelas alturas dos cortes, quando realizados nas idades em estudo.

A maior produção de matéria seca da forrageira ocorreu no período de estiagem daquele ano. Maiores intervalos de cortes possibilitaram produções mais elevadas de massa verde, matéria seca e proteína bruta pela forrageira.

O manejo da capineira deve variar em função dos aspectos climáticos, para que se possa ter melhor aproveitamento da forrageira.

\section{Referências Bibliográficas}

ACUNHA, J.B.V., COELHO, R.W. 1997. Efeito da altura e intervalo de corte do capim-elefante anão. I. Produção e qualidade da forragem. Pesq. Agrop. Bras., 32(1):117-22,

ALCÂNTARA, P.B., ALCÂNTARA, V.B.G., ALMEIDA, J.E. 1980. Estudo de 25 prováveis variedades de capim-elefante (Pennisetum purpureum, Schum.). Bol. Ind. Anim., 37(2):279302.

BOIN C. 1992. Exigências nutricionais de bovinos de corte. In: PEIXOTO, A.M., MOURA, J.C., FARIA, V.P. (Eds.) Curso de alimentação de bovinos. Piracicaba: FEALQ. p.275-288.

BRASIL, Departamento Nacional de Obras Contra a Seca. 1973. Relatório Anual. Recife: DNOSCS. p.47-56.

CANTO, A.C., TEIXEIRA, L. B., MEDEIROS, J.C. et al. 1974. Altura do corte em capim-elefante (Pennisetum purpureum, Schum). Seiva, 34: 83-25.

CARVALHO, L.A. 1985. Pennisetum purpureum, Schumacher: revisão. Coronel Pacheco: EMBRAPA/CNPGL. 86p. (EMBRAPA/CNPGL - Boletim 10).

COSTA, N.L., MAGALHÃES, J.A., PEREIRA, R.G.A. Efeito de regimes de cortes sobre a produção de forragem e composição química de capim-elefante (Pennisetum purpureum, Schum. cv. Mott) In: REUNIÃO ANUAL DA SOCIEDADE BRASILEIRA DE ZOOTECNIA, 32, Brasília, 1995. Anais.... Brasília: SBZ, 1995. p.40-42.

COSTA, R.O., OLIVEIRA, M.E. Avaliação do capim-elefante, submetido a três épocas de corte. In: REUNIÃO DE PESQUISA DO CCA, 3, Teresina, 1993. Anais... Teresina: UFPI, 1993. p.295.

DAHER, R.F., MALDONALDO V.R., FERNANDES, A.M. et al. Competição de clones de capim-elefante (Pennisetum purpureum, Schum.) em Campos dos Goytacazes, RJ. In: REUNIÃO ANUAL DA SOCIEDADE BRASILEIRA DE ZOOTECNIA, 34, Juiz de Fora-MG, 1997. Anais... Juiz de Fora: SBZ, 1997. v.2, p.59-61.

GONÇALEZ, D.A., SILVEIRA, A.C., LAVEZZO, W. et al. Efeitos da maturidade sobre a produção de quatro cultivares de capim-elefante (Pennisetum purpureum). In: REUNIÃO ANUAL DA SOCIEDADE BRASILEIRA DE
ZOOTECNIA, 18, Goiânia, 1981. Anais... Goiânia: SBZ, 1981. p.68.

GONÇALVES, C.A., COSTA, L.C. 1991. Adubação orgânica, frequência de corte de capim-elefante (Pennisetum purpureum. Schum, cv. Cameroon) em Porto Velho, Rondônia. L. Arrozeira, 44(396):27-29.

GUEDES, P.L.C. Influência da época de corte na produtividade $e$ valor nutritivo de quatro cultivares de capim-elefante (Pennisetum purpureum, Schum.), estabelecidas em solo Podzólico Vermelho-Amarelo de Pernambuco. Recife: UFRPE, 1992. 99p. Dissertação (mestrado em Zootecnia) Universidade Federal Rural de Pernambuco, 1992.

NASCIMENTO, I.S. 1997. Comportamento produtivo e qualitativo do capim-elefante (Pennisetum purpureum, Schum) cv. Roxo. Areia, PB: UFPB, 1996. 53p. Monografia (Graduação em Zootecnia) - Universidade Federal da Paraíba, 1996.

NASCIMENTO, I.S., QUEIROZ FILHO, J.L., SILVA, D.S. et al. Avaliação de cultivares de capim-elefante (Pennisetum purpureum, Schum.) no Brejo Paraibano. Ano II - Valor nutritivo. In. ENCONTRO DE INICIAÇÃO CIENETÍFICA DA UFPB, 3, João Pessoa, 1995. Resumos... João Pessoa: UFPB, 1995. p.351.

QUEIROZ FILHO, J.L., SILVA, D.S., NASCIMENTO, I.S. et al. 1998. Produção de matéria seca e qualidade de cultivares de capim-elefante (Pennisetum purpureum, Schum.). R. Bras. Zootec., 27(2):262-266.

SANTOS, E.A., SILVA, D.S., QUEIROZ FILHO. J.L. 2001a. Composição química do capim-elefante cv. Roxo cortado em diferentes alturas. Rev. bras. zootec., 30(1):18-23.

SANTOS, E.A., SILVA, D.S., QUEIROZ FILHO. J.L. 2000 b. Perfilhamento e algumas características morfológicas do capim-elefante cv. Roxo, sob quatro alturas de corte nas duas épocas do ano. Rev. bras. zootec., 30(1):24-30.

SANTANA, J.R., PERERIRA, J.M. ARRUDA, N.G. et al. 1989. Avaliação de cultivares de capim-elefante (Pennisetum purpureum, Schum.) no sul da Bahia. 1. Agrossistema cacaueiro. R. Soc. Bras. Zootec., 18(3):273-83.

SAS - statistical analysis systems. User's guid: Stat, Version 6, 4.ed, v.1/2. Cary North Caroline: SAS Institute, 1993.

SILVA, D.J. 1991. Análise de alimentos (Métodos químicos e biológicos). Viçosa, MG: UFV. 166p.

VERAS, A.S., PAZ, L.G. Produtividade e valor nutritivo de quatro cultivares de capim-elefante (Pennisetum purpureum, Schum.) submetidos a diferentes sistemas de corte. In. SIMPÓSIO DE ALIMENTAÇÃO DE RUMINANTES, 4, Recife, 1994. Anais... Recife: UFPE-SNPA, 1994. p.192.

WERNER, J.C., LIMA F.P., MARTINELLI, D. et al. 1966. Estudos de três diferentes alturas de corte em capim-elefante napier. Bol. Ind. Anim., 23(único):161-68.

Recebido em: 15/05/00

Aceito em: 29/09/00 